\title{
The placebo effect in allergen-specific immunotherapy trials
}

\author{
Annemie Narkus ${ }^{1 *}$, Ulrike Lehnigk ${ }^{1}$, Dietrich Haefner ${ }^{1}$, Regine Klinger ${ }^{2}$, Oliver Pfaar ${ }^{3}$ and Margitta Worm ${ }^{4}$
}

\begin{abstract}
Background: Double-blind, placebo-controlled (DBPC) trials are the gold standard for demonstrating clinical efficacy and tolerability. The placebo effect, although an important feature in placebo-controlled studies, has never been systematically investigated in allergen-specific immunotherapy (SIT) studies. This study was performed to examine the placebo response in SIT trials that employed a baseline observational period and two treatment years using a symptom-medication-score (SMS) as the primary endpoint.

Methods: The placebo effect was evaluated in six DBPC SIT studies (five studies using subcutaneous SIT (SCIT) and one sublingual (SLIT)), two grass, two birch and two house dust mite (HDM) SIT, including a total of 472 adult patients treated with a placebo. The results were reported as changes from baseline of the SMS area under the curve after two years of perennial placebo therapy during the respective evaluation periods. Pollen counts and $\lg G_{4}$ levels were additionally analysed.
\end{abstract}

Results: Subcutaneously treated placebo patients displayed a marked decrease in the SMS. The mean placebo effect in the SCIT trials with comparable allergen exposure was up to $41 \%$ in the second treatment year and, in contrast, reached only $1 \%$ in the SLIT trial. Allergen exposure had an inverse influence on the placebo effect. No changes from baseline in allergen specific $\operatorname{lgG}_{4}$ antibodies were observed in the placebo-treated patients.

Conclusions: SIT studies display a significant placebo effect, mainly observed in subcutaneous immunotherapy, with high variability depending on the route of application and allergen exposure. Our findings indicate the differential role of the placebo effect in SIT efficacy depending on the route of administration and pollen exposure.

Keywords: Allergen-specific immunotherapy, Allergen exposure, Placebo-controlled studies, Placebo effect

\section{Background}

Double-blind, randomised controlled trials provide the highest level of evidence in clinical studies [1]. The major purpose of control groups is to discriminate between experimental group outcomes caused by the active treatment and those that are related to other factors, such as natural progression of the disease, observer or patient expectations or other treatments [2]. Clinical studies can use different types of controls [2], but despite some ethical issues [3], the use of placebos is considered the gold standard to demonstrate clinical efficacy and tolerability for many medicinal products [4].

The placebo design is said to control for all of the potential influences on the course of a disease (other than

\footnotetext{
* Correspondence: annemie.narkus@allergopharma.com

'Medical Department, Allergopharma GmbH \& Co KG, Reinbek, Germany Full list of author information is available at the end of the article
}

those arising from the pharmacologically active treatment). These features include spontaneous improvement (i.e., the natural history of the disease and regression to the mean), subject or investigator expectations, effect of being in a trial, use of other therapies and subjective elements of the diagnosis or assessment. The outcome differences between the pharmacologically active treatment and placebo groups define the treatment effect under trial conditions $[5,6]$.

Allergic diseases are characterised by variable clinical responses because of the unpredictability and variability of allergen exposure and, more importantly, the subjective nature of symptom assessment [7]. Accordingly, double-blind, placebo-controlled trials (DBPC) are recommended by international guidelines for studies investigating the efficacy and safety of allergen-specific immunotherapy (SIT) [8].
C Biomed Central reproduction in any medium, provided the original work is properly cited. The Creative Commons Public Domain Dedication waiver (http://creativecommons.org/publicdomain/zero/1.0/) applies to the data made available in this article, unless otherwise stated. 
The placebo effect is an interesting feature in placebocontrolled studies and refers to the improvement observed in a percentage of patients treated with placebos in a wide range of clinical conditions, either in trials or in clinical practice [9]. It is a genuine psychobiological event attributable to the overall therapeutic context [3]. Psychologically, it is attributed to classical conditioning mechanisms and patient expectations [3,6,10]. Several studies have examined the placebo effect in DBPC studies in trials comparing the placebo with no treatment in different diseases and for different types of outcomes [10-14]. The impact of placebo effects has been described in many reviews [6]. High rates of placebo efficacy were attained in a study with patients with atopic dermatitis [10]. Currently, the placebo effect is discussed in matters of clinical relevance [15]. Because placebos can actually produce results comparable to specific drugs without deception $[10,16]$, it is important to exploit the placebo effect by applying its mechanisms [17] and thus deliberately boosting the efficacy of treatments.

The placebo effect has been analysed in different pharmacologic and placebo treatments in allergic diseases $[7,10,18]$ but never in placebo-controlled SIT clinical trials. In SIT trials, treatment efficacy is usually expressed as the difference between the symptom-medication-score (SMS) in the active treatment group and the placebo group after treatment. A proper evaluation of the placebo effect in SIT trials requires a baseline period to document the effect of exposure and serves as a reference value for calculating changes. SIT trials with a baseline season are limited because they are deemed to be costly and timeconsuming [8].

The aim of this study was to examine the placebo effect in different SIT trials with comparable designs consisting of one observational season (baseline) followed by two treatment years using SMS as the efficacy parameter. Our data highlight the characteristics and clinical relevance of the placebo response and provide relevant information for designing and interpreting future clinical studies in allergen-specific immunotherapy.

\section{Methods}

\section{Study characteristics}

To avoid the well-known heterogeneity of SIT studies and to include in our analysis only comparable trials, we considered in the present analysis all DBPC phase III SIT studies of the company (Allergopharma) that were comparable and homogeneous for all of the following parameters $(n=6)$ : a prospective baseline observation period (a baseline season in the case of pollen studies); the same inclusion and exclusion criteria, as previously recommended [19]; the same baseline patient clinical characteristics (adult patients with allergic rhinitis (AR) with or without bronchial asthma, GINA I and II) [20]; a two-year treatment period; the same evaluation method for allergen exposure; the same length of treatment observation period; a validated method to assess the SMS [21]; the same method for immunological measurements; and the same components and appearance of placebo treatments.

Two studies included patients suffering from a grass pollen allergy, two included patients with a birch pollen allergy and two included patients with a house dust mite (HDM) allergy (Table 1). Five studies were performed with subcutaneous immunotherapy (SCIT), and one used a sublingual extract (SLIT). Three of these studies have been published before [22-25]; data for the remaining three (SCIT HDM 2, SCIT Grasses and SCIT Birch 2) have not yet been published.

For all of the studies ethical and regulatory approval was obtained from the local ethics committee(s) and the local health authorities in the respective countries (United Kingdom, Poland, Germany, Italy, Macedonia, Sweden, and Finland). Written informed consent was obtained from the patient for each of the studies prior to any study related procedure.

The placebo treatment contained all of the constituents of the active product, except for the allergens. In case of SCIT, the placebo contained aluminium-hydroxide, and in three studies, it contained histamine $(0.125 \mathrm{mg} / \mathrm{ml}$ in the highest strength) for blinding.

\section{Assessment}

The results were reported as changes from the baseline of the area under the curve (AUC) of SMS after 2 years of perennial placebo therapy (mean values). The SMS of all of the included studies was based on the validated Allergy Control Score ${ }^{\mathrm{\tau m}}$ [21]. The evaluation periods covered 21 days for birch pollen, 42 days for grass pollen and 28 days for HDM allergies. To compare the subjective and objective outcomes in the placebo group, $\operatorname{IgG}_{4}$ changes in the placebo group were also evaluated.

\section{Assessment of allergen exposure}

Because different pollen exposure levels in different seasons can influence the results, the daily mean AUCs of birch and grass pollen (grains $/ \mathrm{m}^{3}$ ) were assessed during the evaluation periods (https://ean.polleninfo.eu/Ean/). Placebo patients were paired with an allocated pollen trap. The maximum distance between trial centres and pollen stations was $100 \mathrm{~km}$. If one trap provided no results, the closest station with results was chosen for the assessment. Pollen levels were analysed using the median AUC of the pollen count during the assessment period. This period began 10 or 7 days before the pollen peak day and ended 31 days or 13 days after the peak day for grass or birch pollen, respectively. 
Table 1 Characteristics of the evaluated studies and included patients (FAS)

\begin{tabular}{|c|c|c|c|c|}
\hline Extract & Histamine & No. of placebo patients & Age (year, mean, \pm SD) & Gender (M/F) \\
\hline SCIT HDM 1 (22) & + & 62 & $28.6( \pm 9.8)$ & $36 / 26$ \\
\hline SCIT HDM $2 *$ & + & 50 & $32.0( \pm 10.2)$ & $25 / 25$ \\
\hline SCIT Grasses * & + & 87 & $31.7( \pm 9.4)$ & $52 / 35$ \\
\hline SLIT Grasses $(23,25)$ & - & 55 & $34.1( \pm 10.3)$ & $32 / 23$ \\
\hline SCIT Birch 1 (24) & - & 98 & $38.4( \pm 11.4)$ & $45 / 53$ \\
\hline SCIT Birch $2 *$ & - & 120 & $39.0( \pm 11.2)$ & $58 / 62$ \\
\hline
\end{tabular}

Legend: *data on file.

For patients with AR triggered by HDM, a positive HDM exposure with a semi-quantitative biochemical test (Acarex ${ }^{\ominus}$, Davimed Pharma + HealthCare GmbH, Germany ) was performed before and 2 years after therapy to ensure comparable exposure during the baseline and evaluation periods after 2 treatment years.

\section{$\operatorname{lgG}_{4}$ evaluation}

In all studies, $\operatorname{IgG}_{4}$ measurements were performed by the same laboratory using the method described previously [26].

\section{Results}

The six studies included 472 placebo-treated patients (248 males and 224 females; mean age $34 \pm 10.4$ years) (Table 1). A total of 87 patients were treated with SCIT grass pollen placebo, 55 patients were treated with SLIT grass pollen placebo, 218 patients were treated with SCIT birch pollen placebo and 112 patients were treated with SCIT HDM placebo.

A marked SMS decrease in placebo-treated patients was detectable in all but the SLIT trial. Table 2 shows the baseline values for AUC of SMS in these trials and the changes from baseline after the first and second treatment year. Figure 1 displays the mean $\%$ change from baseline for the AUC of SMS in the different studies and treatment years, whereas Figure 2 shows the mean AUC SMS values in the different studies at baseline and during the evaluation periods at one and two treatment years. Patients allergic to pollen showed higher mean daily SMS values at baseline
(14.3/11.5 in the grass trials and 18.9/13.7 in the birch trials) compared to the patients allergic to HDMs (6.5/9).

These data must be matched for the different allergen exposures faced by placebo patients in the different studies and evaluation periods. Table 2 shows the placebo effect in the HDM allergic patients who had a comparable HDM allergen exposure at baseline and at the first and second treatment years. Figure 3 displays the daily mean pollen exposure at baseline and during the pollen seasons after one and two treatment years for grass or birch pollen studies. Grass pollen exposure was similar throughout the study periods in the SLIT trial and resulted in $-1.3 \%$ and $+0.7 \%$ mean changes in AUC SMS (Figure 3A). In the SCIT trial, the grass pollen exposure was much higher during the first season and resulted in a placebo effect of $16.5 \%$; pollen exposure decreased in the second pollen season but was still enhanced compared to baseline resulting in a placebo effect of $-24.7 \%$ (Figure 3B). The pollen exposure in Birch trial 1 showed even higher fluctuations, with reduced exposure in the first treatment year that resulted in a placebo effect of $51.8 \%$, which was followed by an increase in exposure in the second year compared to baseline (a 24.5\% placebo effect) (Figure 3C). Birch pollen exposure was constant in Birch Trial 2. The placebo effect was only $5.9 \%$ in the first treatment year and increased to $18.3 \%$ in the second year (Figure 3D).

For five of the six trials, $\operatorname{IgG}_{4}$ values, which were evaluated using a comparable method, were available. Contrary to the clinical data, the $\operatorname{IgG}_{4}$ levels did not change in placebo patients during the two years of treatment.

Table 2 Changes from baseline as well as changes in the per cent of the AUC of SMS in the placebo group during the studies

\begin{tabular}{|c|c|c|c|c|c|}
\hline \multirow[t]{2}{*}{ Extract } & \multirow{2}{*}{$\begin{array}{l}\text { SMS at baseline } \\
\text { (mean) }\end{array}$} & \multirow{2}{*}{$\begin{array}{l}\text { SMS mean change from baseline } \\
\text { 1st yr }\end{array}$} & \multirow{2}{*}{$\begin{array}{l}\text { SMS mean change from baseline } \\
\text { 2nd yr }\end{array}$} & \multicolumn{2}{|c|}{ Placebo effect SMS \%* } \\
\hline & & & & 1st year & 2nd year \\
\hline SCIT HDM 1 & 181.7 & -44.2 & -53.9 & -24.3 & -29.7 \\
\hline SCIT HDM 2 & 251.7 & -83.7 & -102.0 & -33.2 & -40.5 \\
\hline SCIT grasses & 599.3 & -98.8 & -148.3 & -16.5 & -24.7 \\
\hline SLIT grasses & 484.0 & -6.2 & +3.6 & -1.3 & +0.7 \\
\hline SCIT Birch 1 & 396.9 & -205.5 & -97.4 & -51.8 & -24.5 \\
\hline SCIT Birch 2 & 286.8 & -16.8 & -52.4 & -5.9 & -18.3 \\
\hline
\end{tabular}




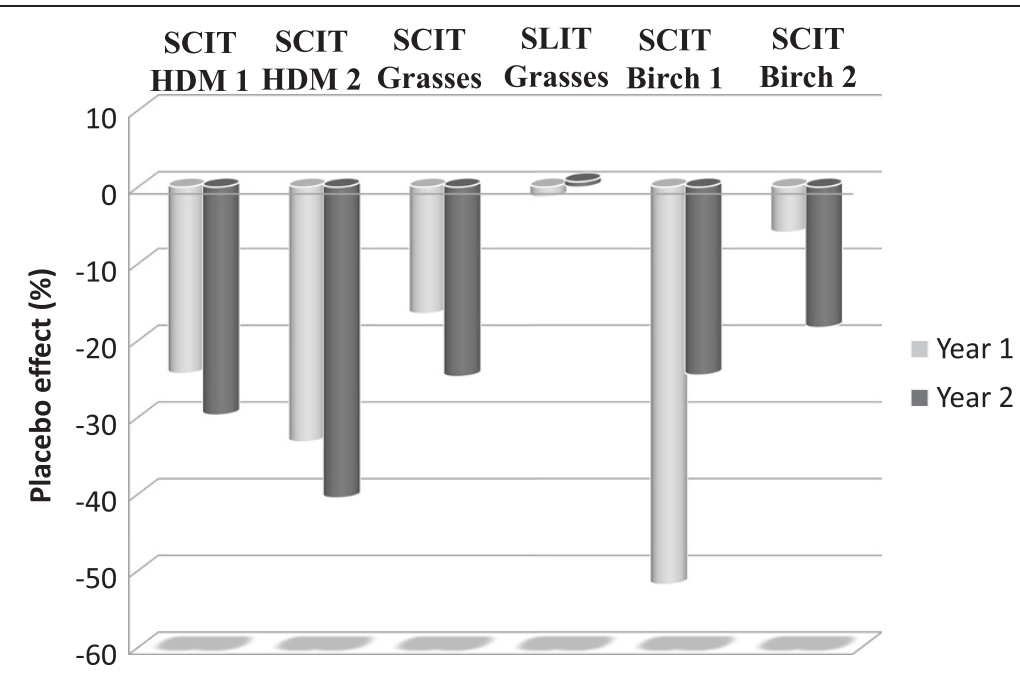

Figure 1 Mean\% change from baseline for the AUC of SMS in the different studies and treatment years.

\section{Discussion}

The present investigation is the first analysis of the placebo response in adult allergic patients enrolled in SIT trials with homogeneous study designs, comparing this response in different allergens and different routes of administration. All of the studies covered a two-year treatment period after a baseline observation phase and used a similar tool to assess efficacy after treatment. Our data showed a high placebo effect in SIT, which was much less prominent in SLIT than in SCIT.

The nervous system and psychological effects are important features of allergic and immunological reactions [7], both in asthma and AR [27,28]. Allergic diseases constitute a group that is highly susceptible to placebo effects, and this effect has been evaluated in placebocontrolled studies of anti-allergic drugs [18].
A meta-analysis of the efficacy of different drug treatments authorised in the United States for allergic rhinitis showed a $15 \%$ improvement in the total symptom score (TSS) for seasonal AR and a 24.8\% improvement for perennial AR in placebo-treated patients [29]. Similar placebo effects have been detected in a meta-analysis evaluating the efficacy of antihistamines, inhaled steroids and a longacting $\beta$-agonist in AR, allergic asthma and atopic dermatitis; the analysis observed an average placebo effect of $23.0 \%$ [7]. A subsequent study investigating the efficacy of different antihistamines compared to placebos in patients with AR found no significant difference between the treatment groups. The physicians' assessments showed 44\% and $40 \%$ overall treatment success rates for the antihistamines fexofenadine $\mathrm{HCl}$ and loratadine, respectively, and a $36 \%$ treatment success rate in the placebo group. The

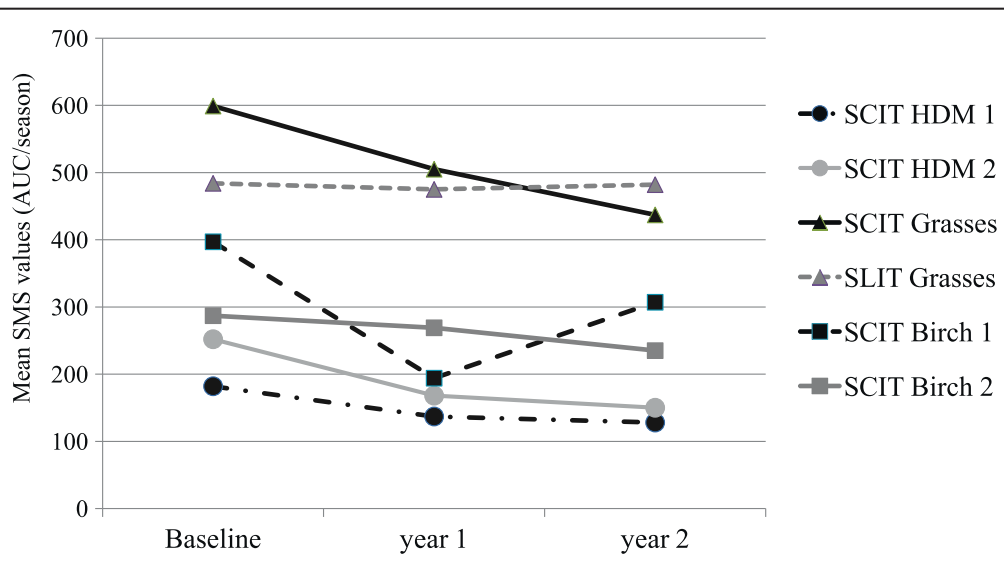

Figure 2 Mean AUC of SMS at baseline after the first and the second treatment year in the placebo groups of the different trials. Legend: the SDs are as follows: SCIT HDM 1 (baseline \pm 104 , first year \pm 112 , second year \pm 109 ), SCIT HDM 2 (baseline \pm 122 , first year \pm 110 , second year \pm 104 ), SCIT grasses (baseline \pm 295 , first year \pm 294 , second year \pm 305 ), SLIT grasses (baseline \pm 218 , first year \pm 321 , second year \pm 300 ), SCIT birch 1 (baseline \pm 156 , first year \pm 133 , second year \pm 168 ), SCIT birch 2 (baseline \pm 131 , first year \pm 162 , second year \pm 168 ). 


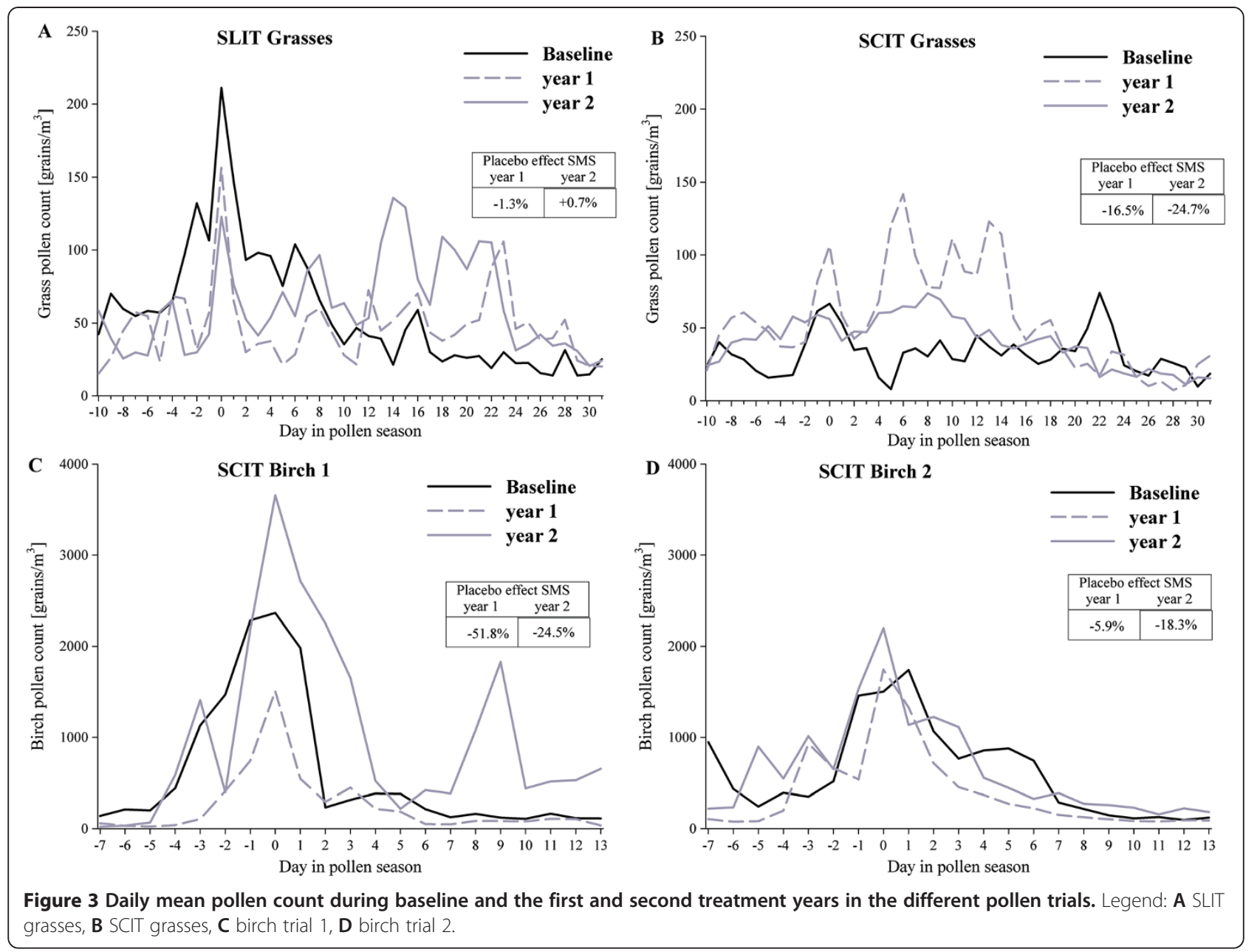

patients' assessments showed treatment success rates of $47 \%, 42 \%$ and $37 \%$, for fexofenadine $\mathrm{HCl}$, loratadine and a placebo, respectively [30].

It is well known that subjective endpoints (e.g., patientreported outcomes and observer-reported outcomes involving patient cooperation) are more susceptible to placebo effects than objective variables [9,13,31]. This finding was also confirmed by our analysis; despite the marked placebo effect in SMS, no change from baseline in allergen specific $\operatorname{IgG}_{4}$ antibodies was observed in the placebo groups.

It has also been reported that the exposure route plays an important role in the magnitude of the placebo effect and that injections cause greater placebo effects than tablets or oral applications [32,33]. An increased placebo response was observed in the five studies using subcutaneous therapy compared with the SLIT study (max. $40.5 \%$ for SCIT versus $1.3 \%$ for SLIT in studies with comparable allergen exposure), which confirms that the administration route may result in different magnitudes of placebo effect in SIT trials. Although we could only include one SLIT trial, other trials support our results, both in studies with comparable pollen counts and in those with comparable mite exposures [34-36]. Ott et al. (35) showed no effect or a worsening in the SLIT placebo group during 3 years of treatment, and a placebo effect could only be observed in the follow-up period due to lower pollen exposure. The very low placebo effect in the SLIT studies is in contrast to the average placebo effect of $23 \%$ for pharmacotherapy of allergic diseases, as shown in a US meta-analysis [7]. One reason for this may be the long duration of SIT trials in contrast to studies with pharmacotherapy where patients will realise the burden of their disease over time. The contribution of the lower SMS in the SLIT versus the SCIT grass trial to the low placebo effect in the SLIT trial seems to be unlikely because even in the other SCIT trials with lower SMS values at baseline, a high placebo effect could be observed. Previous SCIT publications have also reported placebo effects similar to our study. Blumberga et al. [37] found 25\% and $42 \%$ decreases in inhaled steroid use in placebo patients after 2 and 3 years, respectively. Varney et al. [38] observed a 32\% reduction in symptom scores after 1 year of placebo SCIT treatment for patients with mite allergies. 
Walker et al. reported reductions of $15 \%$ in symptom scores and $18 \%$ in medication scores in placebo-treatedpatients with grass allergies, although the pollen exposure was higher in the observation period after the treatment [39]. We could not include these SLIT and SCIT studies in our analysis due to the high heterogeneity of study designs and methods. Furthermore, we excluded studies in children or using pollen chambers because this would have added further complexity.

In addition to the administration route, one reason for the high placebo effects in SCIT may be that, according to clinical guidelines, the placebo must have the exact same composition as the active treatment, except for the allergen. The placebo in the analysed SCIT trials contained aluminium hydroxide and occasionally histamine for blinding. The known adjuvant effect of aluminium hydroxide may have contributed to the placebo effect in SCIT. Furthermore, the high placebo effect in the SCIT trials was a good indication that the blinding was effective in these clinical trials.

A highly important but simple reason for the high placebo effect in SCIT may be the fact that patients are taken care of regularly; they have to come to their physician to receive the injections; the patients and physicians have regular discussions about the disease and treatment, and exacerbations and other issues can be handled immediately. Consequently, patients will generally consider the burden of their disease less severe. The SLIT treatment is home-based, and the patients are left on their own without health care support and again will most likely have a minor placebo effect. However in a study setting, contact with physicians is normally still higher than in daily practice.

The DBPC studies analysed here reported in a prospective manner a baseline period monitored with the same outcomes, methods and scores used for post-treatment evaluation. Unfortunately, the majority of SIT studies do not include a baseline observation. Therefore, they can only assess a final difference between active- and placebotreated patients but not real improvements or the placebo response. Some pollen trials assess baseline values retrospectively, but this method is not suitable because of many biases, the most important being a memory bias [40]. Official documents now recommend the inclusion of a prospective baseline period [41], although the World Allergy Organization states that although the inclusion of a baseline observation is correct in principle, it is not mandatory because it is "expensive and time consuming" [8].

Placebo patients who are allergic to pollen showed higher SMS values compared to patients that are allergic to HDM, most likely because of a reduced awareness of symptoms in perennial exposure. However, even this reduced "room for improvement" resulted in a high placebo effect that was up to $40.5 \%$.
To evaluate placebo effects, the amount of exposure is critical. Our analysis showed that in HDM-allergic patients with comparable exposures between the baseline and the end of the treatment period, the placebo effect in SCIT ranged from $24.3 \%$ to $29.7 \%$ in study 1 and from $33.2 \%$ to $40.5 \%$ in study 2 . With increased exposure, a reduced placebo effect resembling the SCIT grass trial $(16.5 \%$ and $24.7 \%)$ or the second pollen season in Birch trial 1 (24.5\%) was observed. In contrast, a low pollen exposure resulted in a high placebo effect of up to $51.8 \%$ (first year of Birch trial 1). The only exception seemed to be the low placebo effect in the first year of Birch trial 2, although no clear reason was apparent. We have analysed the relationship between changes in the SMS and pollen count and found statistically significant correlations for all studies and all treatment years. Thus, it can be concluded that the amount of allergen exposure is causally related to the magnitude of the placebo effect.

The high placebo effect observed in this SIT analysis must not be ignored and obviously needs further research on the placebo effectiveness in the clinical context of immunotherapy targeting the underlying mechanisms of this genuine psychobiological event. Classical conditioning as well as expectations induced via instructions enable the release of endogenous neurotransmitters, which imitate the expected or conditioned pharmacological effects in the sense of placebo effects $[3,42,43]$. In a sample of patients with atopic dermatitis, we previously showed that an analgesic placebo effect was also established via expectations induced by both mechanisms, i.e., classical conditioning and instructions; however, compared to the healthy control group in the patient group, the effect was maintained only in the groups who experienced classical conditioning [10]. This means that the experience of symptom relief is necessary to learn the placebo effect. Benedetti and colleagues [44] showed that analgesics always consist of two components, a pharmacological and a psychological (placebo) component. They proved this assumption within an alternative model of the double-blind, randomised controlled trials, namely, the "open-hidden paradigm". Here, identical concentrations of active drugs are administered by a physician in an appreciable, e.g., visible (open condition) or hidden, manner (drug given by a computer), in which the patient is unaware of the timing of medication administration. So it is possible to dissociate the pure pharmacological effect of the treatment (hidden treatment) from the additional benefit of the psychological context resulting from knowing that the treatment is being administered. The difference between the outcomes following the administration of the expected and unexpected therapy can be seen as the placebo response or psychological component, even though no placebo treatment has been used. These findings require exploitation of the placebo effect in pharmacological treatment as much as 
possible. Placebo efficacy can be seen as a psychological add-on to the pharmacological component of a medication.

\section{Conclusions}

In conclusion, we detected a placebo effect in SCIT trials from $24 \%$ to $41 \%$ in mite and from $6 \%$ to $25 \%$ in pollen allergic patients with comparable allergen exposure and up to $51.8 \%$ with reduced exposure, which is in contrast to $1.3 \%$ or less in the SLIT trial. The differences between the SCIT and SLIT trials may be explained by the treatment method (i.e., injections versus oral applications) or the ingredients, such as aluminium hydroxide or histamine, included in the placebos in the SCIT trials in order to meet regulatory requirements or to maintain blinding.

This observation underscores the value of a proper baseline observation period in SIT placebo-controlled trials.

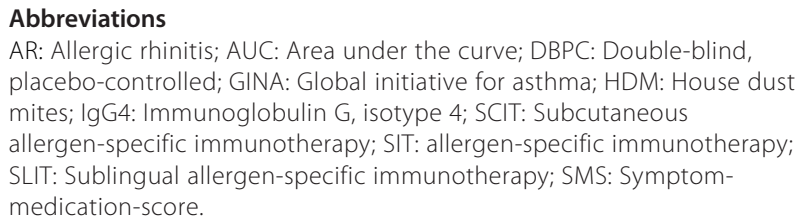

Abbreviations

AR: Allergic rhinitis; AUC: Area under the curve; DBPC: Double-blind, placebo-controlled; GINA: Global initiative for asthma; HDM: House dust mites; IgG4: Immunoglobulin G, isotype 4; SCIT: Subcutaneous allergen-specific immunotherapy; SIT: allergen-specific immunotherapy; SLIT: Sublingual allergen-specific immunotherapy; SMS: Symptommedication-score.

\section{Competing interests}

A. Narkus, U. Lehnigk and D. Haefner are employees of Allergopharma GmbH and Co KG, Reinbek Germany and the studies were performed by Allergopharma $\mathrm{GmbH}$ and $\mathrm{Co} \mathrm{KG}$.

RK, OP and MW declare that they have no competing interests.

\section{Authors' contributions}

AN accounted for the design of the studies and the investigation and drafted the manuscript; UL participated in the design of the investigation as well as the preparation and interpretation of the data; $\mathrm{DH}$ was in charge of the clinical trials and contributed to interpretations of the data; RK, OP and MW participated in designing the investigation and gave interpretations of the data. All authors read and approved the final manuscript.

\section{Author details}

${ }^{1}$ Medical Department, Allergopharma GmbH \& Co KG, Reinbek, Germany. ${ }^{2}$ Department of Clinical Psychology, Behaviour Therapy, University of Hamburg, Hamburg, Germany. ${ }^{3}$ Department of Otorhinolaryngology, Head and Neck Surgery, University Hospital Mannheim, Mannheim, Germany.

${ }^{4}$ Allergy-Center-Charité, Department of Dermatology and Allergy,

Charité-Campus Mitte, Universitätsmedizin, Berlin, Germany.

Received: 13 September 2013 Accepted: 9 December 2013 Published: 21 December 2013

\section{References}

1. Guyatt G, Oxman AD, Akl EA, Kunz R, Vist G, Brozek J, Norris S, Falck-Ytter Y Glasziou P, DeBeer $H$, et al: GRADE guidelines: 1. Introduction-GRADE evidence profiles and summary of findings tables. J Clin Epidemiol 2011, 64:383-394.

2. European Medicines Agency: ICH Topic E 10. Choice of Control Group in Clincal Trials. Note for guidance on choice of control group in clinical trials. CPMP//CH/364/96 2001.

3. Finniss DG, Kaptchuk TJ, Miller F, Benedetti F: Biological, clinical, and ethical advances of placebo effects. Lancet 2010, 375:686-695.

4. European Medicines Agency: EMEA/CPMP Position Statement on the Use of Placebo in Clinical Trials with Regard to the Revised Declaration of Helsinky. London, 28 June 2001. EMEA/17424/01.

5. U.S. Department of Health and Human Services. Food and Drug Administration. Center for Drug Evaluation (CDER). Center for Biologics
Evaluation and Research (CBER): Guidance for Industry. E 10 choice of control group and related issues in clinical trials. ICH 2001.

6. Price DD, Finniss DG, Benedetti F: A comprehensive review of the placebo effect: recent advances and current thought. Annu Rev Psychol 2008, 59:565-590.

7. Radziwill K, Kruszewski J: Evaluation of the size of the placebo effect in treatments of allergic diseases and asthma based on a meta-analysis of efficacy trials of drugs. Post Dermatol Allergol 2011, XXVIII:372-377.

8. Canonica GW, Baena-Cagnani CE, Bousquet J, Bousquet PJ, Lockey RF, Malling HJ, Passalacqua G, Potter P, Valovirta E: Recommendations for standardization of clinical trials with Allergen Specific Immunotherapy for respiratory allergy. A statement of a World Allergy Organization (WAO) taskforce. Allergy 2007, 62:317-324.

9. Hrobjartsson A, Gotzsche PC: Is the placebo powerless? Update of a systematic review with 52 new randomized trials comparing placebo with no treatment. J Intern Med 2004, 256:91-100.

10. Klinger $\mathrm{R}$, Soost $\mathrm{S}$, Flor $\mathrm{H}$, Worm M: Classical conditioning and expectancy in placebo hypoalgesia: a randomized controlled study in patients with atopic dermatitis and persons with healthy skin. Pain 2007, 128:31-39.

11. Walach $\mathrm{H}$ : Placebo controls: historical, methodological and general aspects. Philos Trans R Soc Lond B Biol Sci 2011, 366:1870-1878.

12. Meissner K, Kohls N, Colloca L: Introduction to placebo effects in medicine: mechanisms and clinical implications. Philos Trans $R$ Soc Lond B Bio/ Sci 2011, 366:1783-1789.

13. Hrobjartsson A, Gotzsche PC: Placebo interventions for all clinical conditions. Cochrane Database Syst Rev 2010(1):CD003974. doi: 10.1002/ 14651858.CD003974.pub3.

14. Enck P, Klosterhalfen S, Weimer K, Horing B, Zipfel S: The placebo response in clinical trials: more questions than answers. Philos Trans $R$ Soc Lond B Biol Sci 2011, 366:1889-1895.

15. Enck $P$, Bingel $U$, Schedlowski $M$, Rief $W$ : The placebo response in medicine: minimize, maximize or personalize? Nat Rev Drug Discov 2013, 12:191-204

16. Kaptchuk TJ, Friedlander E, Kelley JM, Sanchez MN, Kokkotou E, Singer JP, Kowalczykowski M, Miller FG, Kirsch I, Lembo AJ: Placebos without deception: a randomized controlled trial in irritable bowel syndrome. PLoS One 2010, 5:e15591.

17. Colloca L, Klinger R, Flor H, Bingel U: Placebo analgesia: psychological and neurobiological mechanisms. Pain 2013, 154:511-514.

18. del Cuvillo A, Sastre J, Bartra J, Mullol J, DaVila I, Montoro J, Ferrer M, Jauregui I, Valero A: Placebo effect in clinical trials involving patients with allergic rhinitis. J Investig Allergol Clin Immunol 2011, 21(Suppl 3):40-45.

19. Alvarez-Cuesta E, Bousquet J, Canonica GW, Durham SR, Malling HJ, Valovirta E: Standards for practical allergen-specific immunotherapy. Allergy 2006, 61(Suppl 82):1-20.

20. Bateman ED, Hurd SS, Barnes PJ, Bousquet J, Drazen JM, FitzGerald M, Gibson P, Ohta K, O' Byrne P, Pedersen SE, et al: Global strategy for asthma management and prevention: GINA executive summary. Eur Respir J 2008, 31:143-178.

21. Häfner D, Reich K, Matricardi PM, Meyer H, Kettner J, Narkus A: Prospective

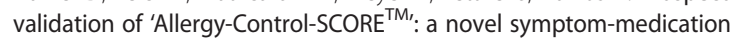
score for clinical trials. Allergy 2011, 66:629-636.

22. Frew A, Schnitker J, Kettner J, Doemer C, Cromwell O, Narkus A: Specific immunotherapy with house dust mites allergoid is safe and clinically efficacious. Allergy Clin Immunol Int 2005, 17(S1):527.

23. Pfaar $\mathrm{O}$, Klimek L: Efficacy and safety of specific immunotherapy with a high-dose sublingual grass pollen preparation: a double-blind, placebocontrolled trial. Ann Allergy Asthma Immunol 2008, 100:256-263.

24. Kettner J, Meyer H, Narkus A, Cromwell O, Jost K: Specific immunotherapy with recombinant birch pollen allergen $r B e t v 1-\mathrm{FV}$ is clinically efficacious - results of a phase III study. Allergy 2007, 62:33.

25. Worm M: Efficacy and tolerability of high dose sublingual immunotherapy in patients with rhinoconjunctivitis. Eur Ann Allergy Clin Immunol 2006, 38:355-360

26. Wahn U, Klimek L, Ploszczuk A, Adelt T, Sandner B, Trebas-Pietras E, Eberle P, Bufe A: High-dose sublingual immunotherapy with single-dose aqueous grass pollen extract in children is effective and safe: a double-blind, placebo-controlled study. J Allergy Clin Immunol 2012, 130:886-893. e885.

27. Bousquet J, Khaltaev N, Cruz AA, Denburg J, Fokkens WJ, Togias A, Zuberbier T, Baena-Cagnani CE, Canonica GW, van Weel C, et al: Allergic Rhinitis and its Impact on Asthma (ARIA) 2008 update (in collaboration 
with the World Health Organization, GA(2)LEN and AllerGen). Allergy 2008, 63(Suppl 86):8-160.

28. Braido F, Baiardini I, Brandi S, Porcu A, Canonica GW: Allergic rhinitis and asthma ad hoc survey: clinical and psychological perspectives. Clin Exp Allergy 2007, 37:788-793.

29. Benninger M, Farrar JR, Blaiss M, Chipps B, Ferguson B, Krouse J, Marple B, Storms W, Kaliner M: Evaluating approved medications to treat allergic rhinitis in the United States: an evidence-based review of efficacy for nasal symptoms by class. Ann Allergy Asthma Immunol 2010, 104:13-29.

30. Van Cauwenberge P, Juniper EF: Comparison of the efficacy, safety and quality of life provided by fexofenadine hydrochloride $120 \mathrm{mg}$, loratadine $10 \mathrm{mg}$ and placebo administered once daily for the treatment of seasonal allergic rhinitis. Clin Exp Allergy 2000, 30:891-899.

31. Meissner K, Distel H, Mitzdorf U: Evidence for placebo effects on physical but not on biochemical outcome parameters: a review of clinical trials. BMC Med 2007, 5:3.

32. de Craen AJ, Tijssen JG, de Gans J, Kleijnen J: Placebo effect in the acute treatment of migraine: subcutaneous placebos are better than oral placebos. J Neurol 2000, 247:183-188.

33. Kaptchuk TJ, Goldman P, Stone DA, Stason WB: Do medical devices have enhanced placebo effects? J Clin Epidemiol 2000, 53:786-792.

34. Lue KH, Lin YH, Sun HL, Lu KH, Hsieh JC, Chou MC: Clinical and immunologic effects of sublingual immunotherapy in asthmatic children sensitized to mites: a double-blind, randomized, placebo-controlled study. Pediatr Allergy Immunol 2006, 17:408-415.

35. Ott H, Sieber J, Brehler R, Folster-Holst R, Kapp A, Klimek L, Pfaar O, Merk H: Efficacy of grass pollen sublingual immunotherapy for three consecutive seasons and after cessation of treatment: the ECRIT study. Allergy 2009, 64:179-186.

36. Tonnel AB, Scherpereel A, Douay B, Mellin B, Leprince D, Goldstein N, Delecluse $P$, Andre C: Allergic rhinitis due to house dust mites: evaluation of the efficacy of specific sublingual immunotherapy. Allergy 2004 59:491-497.

37. Blumberga G, Groes L, Haugaard L, Dahl R: Steroid-sparing effect of subcutaneous SQ-standardised specific immunotherapy in moderate and severe house dust mite allergic asthmatics. Allergy 2006, 61:843-848.

38. Varney VA, Tabbah K, Mavroleon G, Frew AJ: Usefulness of specific immunotherapy in patients with severe perennial allergic rhinitis induced by house dust mite: a double-blind, randomized, placebo-controlled trial. Clin Exp Allergy 2003, 33:1076-1082.

39. Walker SM, Pajno GB, Lima MT, Wilson DR, Durham SR: Grass pollen immunotherapy for seasonal rhinitis and asthma: a randomized, controlled trial. J Allergy Clin Immunol 2001, 107:87-93.

40. Casale TB, Canonica GW, Bousquet J, Cox L, Lockey R, Nelson HS, Passalacqua G: Recommendations for appropriate sublingual immunotherapy clinical trials. J Allergy Clin Immunol 2009, 124:665-670.

41. European Medicines Agency: Guideline On The Clinical Development Of Products For Specific Immunotherapy For The Treatment Of Allergic Diseases. London, 20 November 2008. Doc Ref CHMP/EWP/18504/2006.

42. Riether C, Doenlen R, Pacheco-Lopez G, Niemi MB, Engler A, Engler H, Schedlowski M: Behavioural conditioning of immune functions: how the central nervous system controls peripheral immune responses by evoking associative learning processes. Rev Neurosci 2008, 19:1-17.

43. Albring A, Wendt L, Benson S, Witzke O, Kribben A, Engler H, Schedlowski M: Placebo effects on the immune response in humans: the role of learning and expectation. PLOS One 2012, 7:e49477.

44. Colloca L, Lopiano L, Lanotte M, Benedetti F: Overt versus covert treatment for pain, anxiety, and Parkinson's disease. Lancet Neurol 2004, 3:679-684.

doi:10.1186/2045-7022-3-42

Cite this article as: Narkus et al:: The placebo effect in allergen-specific immunotherapy trials. Clinical and Translational Allergy 2013 3:42.

\section{Submit your next manuscript to BioMed Central and take full advantage of:}

- Convenient online submission

- Thorough peer review

- No space constraints or color figure charges

- Immediate publication on acceptance

- Inclusion in PubMed, CAS, Scopus and Google Scholar

- Research which is freely available for redistribution

Submit your manuscript at www.biomedcentral.com/submit
() Biomed Central 